\title{
Antibody-mediated rejection across solid organ transplants: manifestations, mechanisms, and therapies
}

\author{
Nicole M. Valenzuela and Elaine F. Reed \\ UCLA Immunogenetics Center, Department of Pathology and Laboratory Medicine, UCLA, Los Angeles, California, USA.
}

Solid organ transplantation is a curative therapy for hundreds of thousands of patients with end-stage organ failure. However, long-term outcomes have not improved, and nearly half of transplant recipients will lose their allografts by 10 years after transplant. One of the major challenges facing clinical transplantation is antibody-mediated rejection (AMR) caused by anti-donor HLA antibodies. AMR is highly associated with graft loss, but unfortunately there are few efficacious therapies to prevent and reverse AMR. This Review describes the clinical and histological manifestations of AMR, and discusses the immunopathological mechanisms contributing to antibody-mediated allograft injury as well as current and emerging therapies.

\section{Introduction}

Solid organ transplantation is a lifesaving, curative therapy for patients with end-stage kidney, heart, liver, lung, pancreas, or bowel disease. More than 100,000 patients await a transplant from the deceased-donor pool in the United States. In 2015, 30,000 patients received an organ transplant (organdonor.gov; ref. 1). Based on Organ Procurement and Transplantation Network (OPTN) data (February 15, 2017), more than $90 \%$ of renal allografts in the United States are still functioning by 1 year after transplant. However, the lifetime of allografts does not match the life expectancy of patients. Twenty percent of recipients will lose their graft within 5 years, and 50\% within 10 to 12 years. Many other organs fare worse; for example, lung allograft survival at 5 years is only $50 \%$ (http://optn.transplant.hrsa.gov). Moreover, although the number of patients who need a transplant has steadily grown in the last two decades, the number of organ donors per year is stagnant (organdonor.gov). Therefore, it is of high interest to extend the survival of transplanted solid organs and the patients who receive them.

A major driver of organ transplant injury is the alloimmune response, predominantly to polymorphic HLA. HLA allosensitization occurs after exposure to non-self tissue, through pregnancy, cardiac mechanical assist device placement, transfusion, solid organ transplantation, and tissue grafting (e.g., burn patients, homograft repair of congenital heart defects, or coronary artery bypass graft). The pathogenic role of alloantibodies in solid organ transplantation was recognized in the 1960s, when Patel and Terasaki (2) seminally showed that donor-specific antibodies, detected by cytotoxic crossmatch, were associated with immediate failure of renal allografts. Since this era, advances in the detection of antibodies against HLA, the diagnosis of antibody-mediated rejection (AMR), and our knowledge of the mechanisms of antibody-mediated allograft injury have expanded our understanding of AMR.

Conflict of interest: E.F. Reed received research grant funding from CSL Behring and Immucor Inc. E.F. Reed is an inventor on US Patent Publication No. 20170030928. Reference information: J Clin Invest. 2017;127(7):2492-2504.

https://doi.org/10.1172/JCI90597.
According to OPTN data, approximately $60 \%$ of the US renal transplant waitlist is sensitized to HLA, with an overrepresentation of women and retransplant candidates. In the post-transplant period, production of donor-specific antibodies against HLA (DSAs) among previously nonsensitized adult renal allograft recipients is $7 \%$ by 5 years (3) and nearly $20 \%$ after 10 years (4-6). The incidence tends to be higher (up to $40 \%$ ) in pediatric $(7,8)$ and medicationnonadherent adult transplant patients, with the latter constituting nearly two-thirds of adult transplant patients by 12 years after transplantation (6). Post-transplant DSAs are also produced by a significant proportion of heart (9), lung (10), liver (11), and intestinal transplant recipients (12). Risk factors for de novo DSA (dnDSA) production also include recipients of African American ethnicity, episodes of acute cell-mediated rejection in the first year after transplant $(3,6)$, donor-recipient mismatching for HLA-DQ (3), and pretransplant sensitization to HLA (nondonor) (4).

Patients transplanted with preformed DSAs are at higher risk of acute AMR, chronic rejection, and allograft loss across all solid organs $(8,10,12-22)$. AMR prevalence among presensitized patients is more than $20 \%$ (23). Production of dnDSAs after any solid organ transplantation is a major risk factor for decreased long-term graft survival. By 5 years after the appearance of dnDSAs, $40 \%$ of patients lose their renal allografts, compared with better than $80 \%$ survival of patients without DSAs (6). Half to all of late allograft failures can be attributed to HLA DSAmediated chronic rejection (4, 24-28).

This Review will focus on the clinical impact and mechanisms of AMR mediated by antibodies against classical HLA molecules, and discuss the current and emerging therapies to prevent and combat AMR.

\section{Manifestations and mechanisms of acute AMR}

Acute T cell-mediated rejection typically responds well to increased immunosuppression, while AMR is poorly responsive to standard therapy. Diagnostic criteria for AMR were first established for renal and heart allografts $(29,30)$, and subsequently for pancreas, liver, and lung allografts (31-33). Features of AMR in bowel and vascularized composite tissue allografts (CTAs) have been described 
Table 1. The overarching features of AMR for cardiac, renal, pancreas, liver, lung, bowel, and composite tissue allografts

\begin{tabular}{|c|c|c|c|c|c|c|c|}
\hline \multirow[b]{2}{*}{$\begin{array}{l}\text { Organ/ } \\
\text { Tissue }\end{array}$} & \multicolumn{7}{|c|}{ Features of acute antibody-mediated rejection } \\
\hline & $\begin{array}{l}\text { Consensus } \\
\text { criteria }\end{array}$ & $\begin{array}{l}\text { Evidence of HLA } \\
\text { DSAs needed }\end{array}$ & $\begin{array}{l}\text { Concurrent allograft } \\
\text { dysfunction needed }\end{array}$ & C4d & $\begin{array}{l}\text { Microvascular } \\
\text { inflammation }\end{array}$ & $\begin{array}{l}\text { Immune cell } \\
\text { infiltration }\end{array}$ & Notes \\
\hline Heart & Yes $(29,39)$ & $\begin{array}{l}\text { May or may not } \\
\text { be present; but } \\
\text { consideration to } \\
\text { return to criteria } \\
\text { (40) }\end{array}$ & $\begin{array}{l}\text { No; may be clinical } \\
\text { or subclinical }\end{array}$ & $\begin{array}{l}\text { May or may not } \\
\text { be present; linear } \\
\text { capillary staining } \mathrm{I}^{\mathrm{A}} \\
\text { if positive }\end{array}$ & $\begin{array}{l}\text { May or may not be } \\
\text { present; "EC swelling," } \\
\text { dilation, } C D 31 \mathrm{~h}+{ }^{\mathrm{A}} \\
\text { if positive }\end{array}$ & $\begin{array}{l}\text { May or may not be } \\
\text { present; intracapillary } \\
\text { CD68 macrophages } \\
\text { and other IAMCs }\end{array}$ & $\begin{array}{l}\text { Not all are required } \\
\text { for a definitive } \\
\text { diagnosis }\end{array}$ \\
\hline Pancreas & Yes (32) & $\begin{array}{l}\text { Yes; required } \\
\text { (HLA); "suspicious" } \\
\text { if missing }\end{array}$ & $\begin{array}{c}\text { Unknown; in ref. 192, } \\
\text { all were for-cause } \\
\text { biopsies }\end{array}$ & Yes; only if in IACs & $\begin{array}{l}\text { Acinar injury, cytoplasmic } \\
\text { swelling, vacuolization, } \\
\text { capillary dilatation }\end{array}$ & $\begin{array}{l}\text { Interacinar capillaritis } \\
\text { with mononuclear cells } \\
\text { or PMNs; CD68 can } \\
\text { be helpful }\end{array}$ & $\begin{array}{l}\text { C4d alone is } \\
\text { insufficient but } \\
\text { with MVI }\end{array}$ \\
\hline Liver & $\begin{array}{l}\text { Yes (31); others: } \\
\text { refs. 100, } 118\end{array}$ & $\begin{array}{c}\text { Yes; } \\
\text { required (HLA) }\end{array}$ & $\begin{array}{l}\text { Unknown; studies report } \\
\text { only for-cause biopsies, } \\
\text { since protocol biopsy } \\
\text { of this organ is rare }\end{array}$ & $\begin{array}{l}\text { Yes; diffuse, }>50 \% \\
\text { portal tract staining } \\
\text { microvasculature, with } \\
\text { or without sinusoidal } \\
\text { or central vein } \\
\text { involvement }(98,100)\end{array}$ & $\begin{array}{l}\text { Yes; portal microvascular } \\
\text { endothelial hypertrophy, } \\
\text { portal capillary and } \\
\text { inlet venule dilatation }\end{array}$ & $\begin{array}{l}\text { Monocytic, eosinophilic, } \\
\text { and/or neutrophilic } \\
\text { portal microvasculitis; } \\
\text { CD68 less informative } \\
\text { in this organ }\end{array}$ & \\
\hline Intestine & № (193) & $\begin{array}{l}\text { Recommended } \\
\text { (35) }\end{array}$ & $\begin{array}{c}\text { Unknown; lack of } \\
\text { consensus: yes (194), no } \\
\text { (195) }\end{array}$ & Recommended (35) & $\begin{array}{l}\text { Possibly; capillary } \\
\text { dilatation and } \\
\text { congestion (196) }\end{array}$ & $\begin{array}{l}\text { Adherent inflammatory } \\
\text { cells in vessels; more } \\
\text { severe rejection with } \\
\text { transmural inflammation } \\
\quad(195,196)\end{array}$ & $\begin{array}{l}\text { Not well defined } \\
\text { because of nonspecific } \\
\text { C4d staining and } \\
\text { paucity of vessels in } \\
\text { biopsies }\end{array}$ \\
\hline $\begin{array}{l}\text { Composite } \\
\text { tissue }\end{array}$ & $\begin{array}{l}\text { No; early mention } \\
\text { in ref. } 34 \text {, but AMR } \\
\text { is not part of these } \\
\text { Banff } 2007 \text { criteria }\end{array}$ & Unknown & $\begin{array}{l}\text { Unknown; not } \\
\text { enough clear evidence }\end{array}$ & $\begin{array}{c}\text { May not be } \\
\text { informative (99) }\end{array}$ & $\begin{array}{c}\text { Possibly; } \\
\text { vasculitis (34) }\end{array}$ & Neutrophil margination & \\
\hline
\end{tabular}

Where consensus criteria have been described, the most recent citation is given. Where consensus criteria have not yet been published (intestine and composite tissue), relevant references describing putative features of AMR in these organs are given. AFor cardiac transplantation, "pathological" AMR (pAMR) may be diagnosed in the setting of histological evidence of allograft injury $(h+)$, such as capillary endothelial changes, and/or immunopathological evidence of AMR ( $\mathrm{i}+$ ), such as positive C4d staining. EC, endothelial cell; IACs, interacinar capillaries; IAMCs, intracapillary activated mononuclear cells; MVI, microvascular inflammation; PMN, polymorphonuclear cells, such as neutrophils; PTC, proximal tubule cell.

$(34,35)$, but consensus criteria for AMR in these tissues are still needed. Although growing evidence shows that antibodies to nonHLA antigens contribute to allograft dysfunction (36-38), no clear diagnostic criteria for non-HLA AMR have been established. Table 1 provides an overview of the current and proposed consensus criteria for the diagnosis of HLA AMR across solid organs and CTAs. Notably, four overarching features form the cornerstone of acute AMR diagnosis in transplanted solid organs (Table 1): serological evidence of antibodies, histological evidence of endothelial cell injury, complement activation, and infiltration of innate immune cells. These common features of AMR are discussed below in a framework to inform regarding their use for diagnosis, treatment, and understanding of the mechanisms of AMR.

\section{HLA donor-specific antibodies}

Diagnostic tools. The presence of circulating DSAs is required for the diagnosis of AMR in renal (30), pancreas (32), liver (31), and lung (33) transplantation. Currently, diagnosis of AMR in cardiac allografts does not require this "serological" component (39), but it may be reintroduced (40) with the acknowledgement that either HLA DSAs or non-HLA antibodies may contribute to AMR.

Detection of HLA antibodies uses a multiplexed assay with nearly 200 HLA antigens coupled to fluorescent beads to characterize an individual's alloantibody repertoire. Extraordinarily high levels of pretransplant DSAs (greater than 10,000 median fluorescence intensity units [MFI] in our experience), especially against HLA class I antigens, may be cytotoxic and place patients at risk of hyperacute rejection. Patients are more likely to experience worse outcomes with stronger pretransplant DSA $(21,41)$. After transplant, DSAs of 2,500-3,000 MFI or above at the time of biopsy-proven rejection are associated with worse long-term outcome $(42,43)$ and increased incidence of AMR (3). Additionally, the persistence of DSAs is associated with worse outcome $(19,44)$. 
A

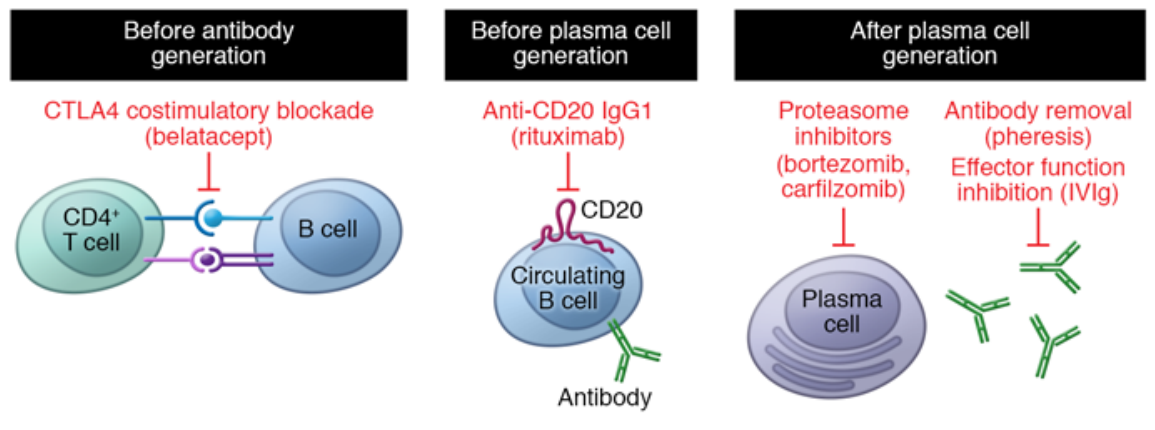

B
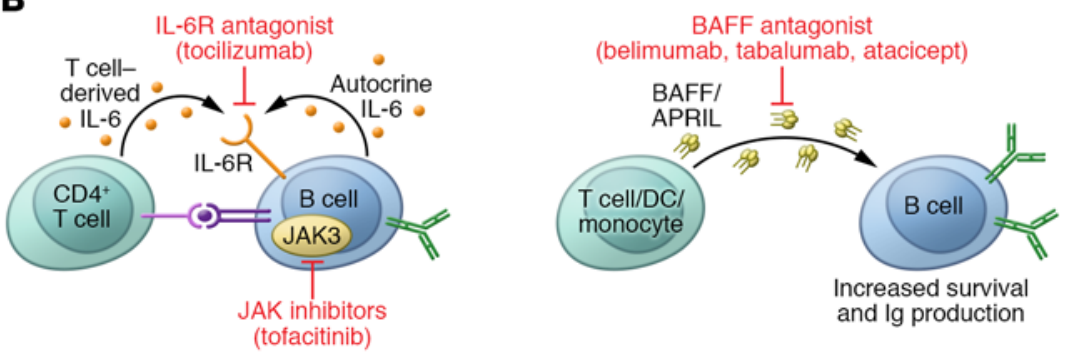

Figure 1. Current and emerging therapies to prevent HLA antibody production. (A) Naive B cells rely on signals from $\mathrm{CD}^{+} \mathrm{T}$ cells for full activation, Ig class switching, and Ig production. Blockade of costimulation using the CTLA4 fusion protein belatacept inhibits this important signal and hampers $B$ cell activation. Naive as well as antigen-experienced B cells may be depleted from the circulation with antibodies against CD20, such as rituximab. Once HLA antibody-producing B cells have differentiated into plasma cells, they are more difficult to target. Because these antibody "factories" are metabolically active and reliant on the function of the proteasome, inhibitors such as bortezomib and carfilzomib, which block the 205 proteasome, may trigger apoptosis of these cells. Bortezomib is a reversible inhibitor, while carfilzomib is irreversible. Antibodies may also be physically removed from the circulation with plasmapheresis, and their effector functions inhibited by intravenous immunoglobulin (IVIg). (B) Emerging therapies to reduce alloantibody production include antagonism of the IL-6 receptor (tocilizumab), BAFF (belimumab, tabalumab, atacicept), and inhibition of intracellular JAK (tofacitinib), which are needed for B cell activation and Ig production. BAFF/APRIL, $B$ cell-activating factor/a proliferation-inducing ligand.

Solid-phase assays to detect HLA antibodies, although quite sensitive, may not predict the true pathogenic potential of DSAs. Several modifications of the HLA single-antigen test have been introduced that may provide useful information on the effector function of the DSA. In vitro assays measure binding of C1q (45) or deposition of C3d $(46)$ or C4d $(47,48)$ to single-antigen beads, enabling identification of potentially complement-activating antibodies as well as their HLA specificity. The prognostic value of these assays remains controversial $(5,7,20,49-52)$, in part because in vitro complement activity appears to be tightly tied to antibody titer $(20,44,53,54)$.

Human IgG is composed of four subclasses. The subclass repertoire is potentially more informative for assessing the pathogenicity of DSAs than complement assays, as subclass predicts complement activation, Fc $\gamma$ receptor-dependent (Fc $\gamma$ R-dependent) functions, and the immunobiology of the alloantibody response. A growing number of reports suggest that characterization of DSA IgG subclass may have utility in identifying patients at risk of rejection or graft loss $(5,55-60)$. While enlightening, these studies have yet to capture the impact of mixtures of subclasses or multiple concurrent DSA specificities. It will be interesting to see how
HLA IgG subclasses evolve longitudinally and correlate with graft pathology in transplant patients.

The human immune response is dynamic. Some patients exhibit "natural" or false-positive reactivity with recombinant HLA antigens (61), which do not detrimentally affect allograft outcome (62). On the other hand, patients with a known history of sensitization events may not exhibit detectable circulating anti-HLA antibodies at the time of transplant evaluation. This has prompted development of alternative methods to measure alloreactivity, including an HLA-specific B cell enzyme-linked immunospot (ELISPOT) $(63,64)$, ex vivo stimulation of B cells $(65$, 66 ), and staining of peripheral B cells with HLA tetramers (67). More work is needed to understand the clinical relevance of alloreactive memory B cells in the absence of circulating HLA DSAs.

Therapies. Nonadherence to maintenance immunosuppression is an important risk factor for dnDSA production in a number of studies $(6,68)$, suggesting that $\mathrm{T}$ cell inhibition is at least partly efficacious in delaying alloantibody formation. However, typical maintenance therapies (such as tacrolimus or mycophenolate) have little to no known effect on memory B cells or plasma cells.

Costimulatory blockade reduces the incidence of dnDSA production. Treatment of mice with cytotoxic $\mathrm{T}$ lymphocyte-associated protein-4-Ig (CTLA4-Ig) prevented alloantibody production when given in the first 2 weeks after sensitization $(69,70)$. Similarly, the CTLA4-Ig fusion protein belatacept reduced the risk of dnDSA formation in low-risk transplant patients (71). However, once patients present with preformed or de novo HLA antibodies, they become more challenging to manage. In combination with i.v. immunoglobulin, which has numerous proposed mechanisms of action (72), plasmapheresis can be effective at temporarily reducing circulating HLA antibodies. Peripheral B cells can be depleted with rituximab or other antiCD20 immunotherapies (73). Eighty percent of highly sensitized transplant candidates responded to rituximab-based desensitization, enabling transplantation in patients who may otherwise have waited longer and possibly died before receiving an organ (74).

Importantly, CD20-directed biologics have little effect on the plasma cells responsible for the majority of serum antibodies. Peripheral concentrations of $\operatorname{IgG}$ are mostly unaltered in patients after rituximab treatment, despite depletion of more than $95 \%$ of circulating B cells (75). Thus, other therapies are needed to target the antibody-producing plasma cells within bone marrow niches. Proteasome inhibitors such as bortezomib (76) and carfilzomib (77) may more effectively target metabolically active plasma cells. On its own, a single dose of bortezomib is insufficient to reduce 
A

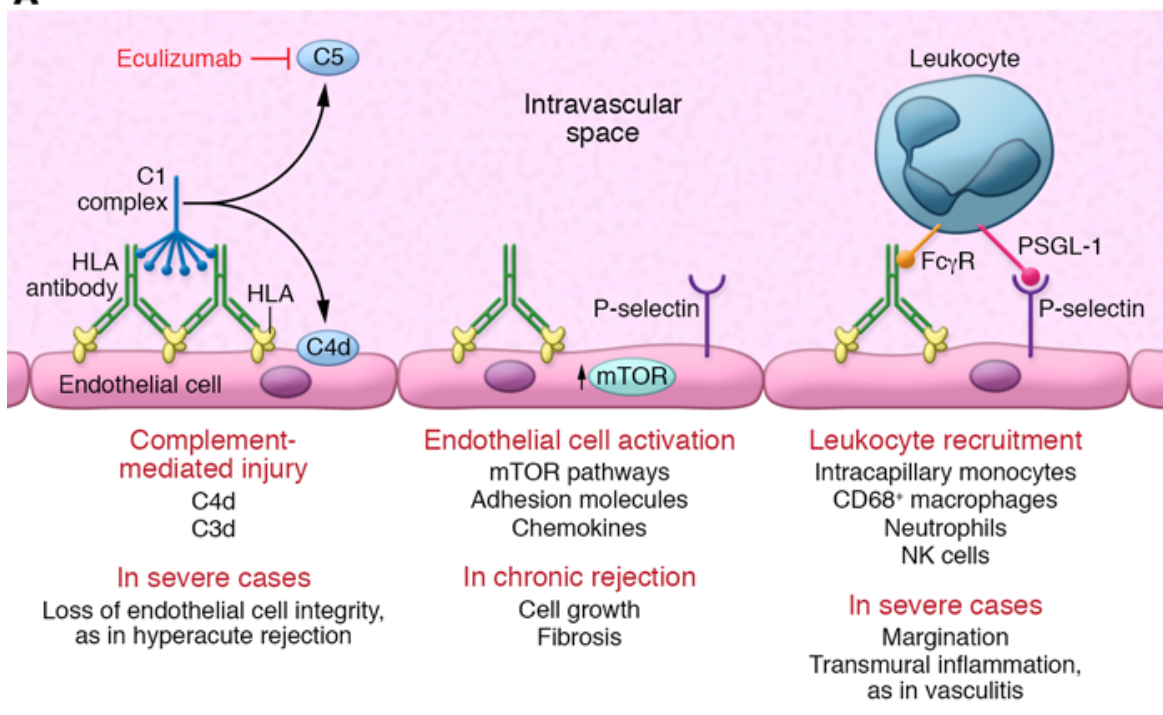

B
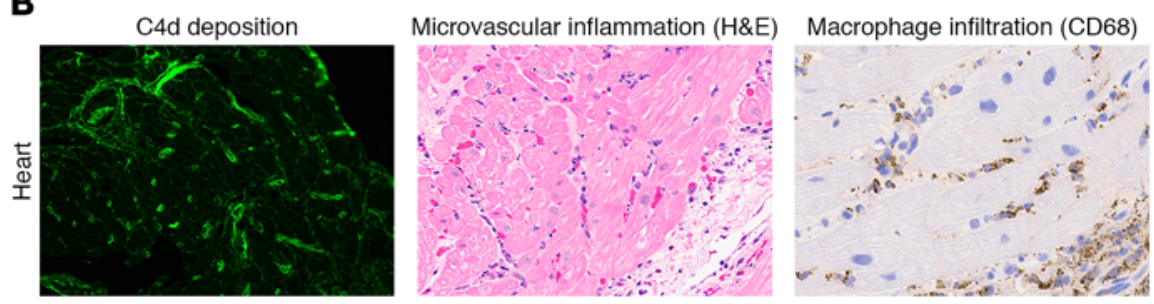

C4d deposition

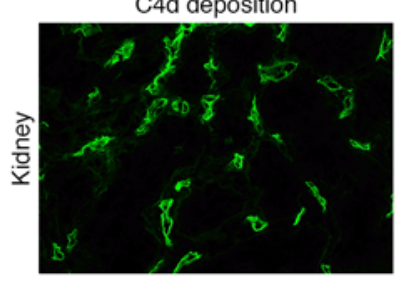

Microvascular inflammation (EM)

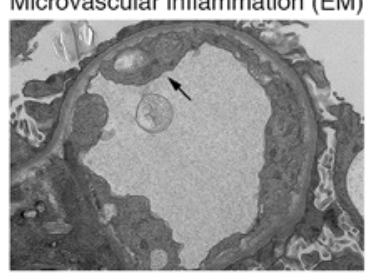

Figure 2. The known mechanisms of HLA antibody-mediated allograft injury and their therapeutic targets. (A) HLA antibody binding to donor endothelial cells can trigger activation of the classical complement cascade. First, the complement $\mathrm{C} 1$ complex, which includes $\mathrm{C} 1 \mathrm{q}, \mathrm{C} 1 \mathrm{r}$, and $\mathrm{C} 1 \mathrm{~s}$, binds to the IgC heavy chain Fc region. The $\mathrm{C} 1$ complex next sequentially activates serum complement proteins, catalyzing the generation of immunologically active split products. Activation of complement $C 5$ protein occurs at the terminal stage of the signaling pathway, generating the highly potent anaphylatoxin $\mathrm{C} 5 \mathrm{a}$ and initiating assembly of the membrane attack complex (MAC). In the process, the split product C4d becomes covalently bound to the endothelial cell surface and can be detected in biopsies of allografts undergoing rejection through immunofluorescent or immunohistochemical staining. Eculizumab is an mAb that prevents $\mathrm{C5}$ cleavage. HLA binding also activates intracellula signaling within the donor endothelium, mainly via the MTOR signaling axis, and upregulation of the adhesion molecule P-selectin. P-selectin, in conjunction with the interaction between immune cell Fc $\gamma$ receptors (Fc $\gamma R s$ ), enhances leukocyte-endothelial adhesion. PSCL-1, P-selectin glycoprotein 1. (B) Representative micrographs illustrating the three main histological features of AMR in heart (top panels) and kidney (bottom panels) allografts. Deposition of C4d within the microvasculature is visualized by immunofluorescence in green. H\&E staining demonstrates increased capillary endothelial cell size and numerous leukocytes in the intravascular space. Immunohistochemical staining for CD68 highlights intracapillary macrophages (original magnification, $\times 400$ ). EM, electron micrograph.
DSA levels (78), but when bortezomib was combined with plasmapheresis and rituximab, $40 \%$ of renal transplant candidates with DSAs were successfully desensitized (76). Patients who undergo desensitization have higher rejection rates (79), but long-term outcomes are comparable to those of lower risk patients $(80,81)$. Figure $1 \mathrm{~A}$ presents the stages at which $\mathrm{B}$ cell production of HLA antibodies may be targeted.

Tabalumab is an $\mathrm{mAb}$ that neutralizes $\mathrm{B}$ cell activating factor (BAFF/BLyS), a critical B cell factor. Disappointing results from clinical trials suggest that, on its own, BAFF antagonism is ineffective to durably reduce HLA antibody levels (82). However, given that higher BAFF levels are associated with greater sensitization to HLA $(83,84)$ and AMR $(85)$, it remains an intriguing therapeutic target in the quest for suppressors of HLA antibody production. Another BAFF antagonist, atacicept, reduced dnDSA production in a nonhuman primate model of renal transplantation (86), and belimumab, which showed efficacy in systemic lupus erythematosus (87), is being investigated to reduce pretransplant HLA allosensitization (NCT02500251, ClinicalTrials.gov).

Tocilizumab is an mAb antagonist of the IL-6 receptor, which is critical in B cell activation and antibody production. Half of sen- sitized kidney transplant patients who had failed desensitization with other methods experienced tocilizumab-induced reductions in HLA antibodies that facilitated transplant (88). Therefore, IL-6 antagonism appears useful in restraining HLA antibody production in sensitized individuals (Figure 1B), and may also be useful as a therapy for chronic AMR (89).

Finally, cytokine signaling in immune cells is dependent on intracellular actions of JAKs (Figure 1B). One example is JAK3, which is important for activation and Ig production in naive B cells (90). Although trials of the JAK inhibitor tofacitinib were halted because of adverse events (91), recent reviews have advocated reconsideration of the suitability of this and other JAK inhibitors in maintenance immunosuppression for transplant (92).

To summarize, there is a need for additional approaches to prevent alloantibody generation and more effective therapies to specifically deplete DSA-producing B and plasma cells.

\section{Complement deposition}

Diagnosis. Figure 2 illustrates the mechanisms of allograft injury by HLA donor-specific antibodies, and provides exemplary histological images of AMR features in cardiac and renal allografts. His- 


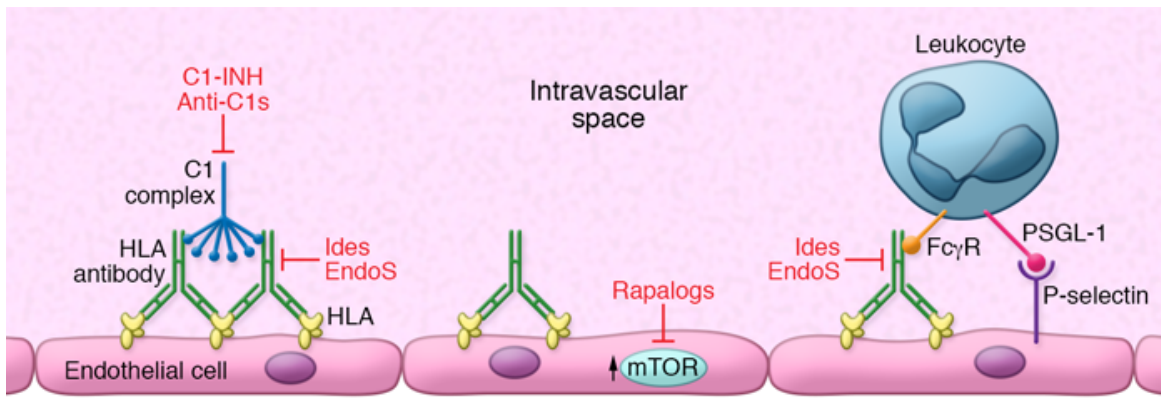

Figure 3. Emerging therapies to inhibit HLA antibody-induced allograft injury. Emerging therapies for AMR include upstream complement inhibition with C1 esterase (C1-INH) or antibody against C1s. DSAs are capable of cross-linking HLA molecules on the donor endothelial and smooth muscle cells, resulting in activation of the mTOR signaling axis. Rapamycin (sirolimus) and other rapalogs (everolimus) inhibit mTOR and may dampen vascular cell growth and fibrosis, which contributes to chronic rejection. Finally, abolishing Fc-dependent antibody effector functions through cleavage of the Fc region with IdeS, or removal of the $\mathrm{N}$-linked glycan with EndoS, is likely to hamper activation of the classical complement cascade as well as prevent interactions with Fc $\gamma$ Rs on monocytes, neutrophils, and NK cells.

tological detection of endothelial membrane-associated complement split product $\mathrm{C} 4 \mathrm{~d}$ is widely used to provide evidence of DSA interaction with the allograft vasculature, first described in refs. 93 and 94. C4d is a reliable and specific, but not sensitive, marker of AMR in heart, kidney, and pancreas allografts when deposited in the capillaries. C4d may be nonspecifically positive in larger vessels or the interstitium. In contrast, there is a lack of consensus regarding the utility of C4d staining in lung (95-97), visceral, liver, and composite tissue transplantation, although it has been recommended in conjunction with other indicators of antibody-mediated graft injury $(31,35,98-100)$. C4d positivity is considered but not required for a diagnosis of AMR in cardiac and renal allografts, and C4d detection often misses cases of AMR (101-103).

Mechanisms and therapies. Antibodies interacting with their targets may activate the classical complement cascade, the initiation of which is regulated by the $\mathrm{C} 1$ complex that binds to the Fc portion of IgG. The complement pathway is a sequential series of amplified catalytic events leading to activation of successively more potent serum complement factors. The end result of terminal complement activation is generation of the potent anaphylatoxin C5a and formation of the membrane attack complex (MAC). Even during acute AMR, MAC-mediated cell lysis is uncommon. Endothelial cells, which are constantly exposed to serum complement factors, express a repertoire of cell surface complement regulatory proteins (CD59, DAF, Crry) that actively antagonize and limit complement activation. Complement activation is also negatively regulated by serum factors, such as the serpin C1 esterase (C1-INH).

At sublytic levels, MAC has been shown to activate noncanonical NF- $\kappa \mathrm{B}$ signaling in endothelial cells, leading to cytokine and adhesion molecule expression (104). Upstream complement components such as $\mathrm{C} 3 \mathrm{a}, \mathrm{C} 3 \mathrm{~b}$, and C5a are physiologically active and act on both endothelial cells and leukocytes to enhance inflammation (105). Eculizumab is a recombinant antibody against complement C5. Eculizumab may facilitate transplantation across high levels of donor-specific antibodies (106) and be effective as salvage therapy for aggressive AMR (107). However, patients treated with eculizumab remain at risk of acute AMR and chronic rejec- tion $(108,109)$. These findings suggest that upstream complement activation and/or non-complement-mediated effector functions mediate allograft damage.

Emerging therapies to suppress activation of complement include those that act at earlier points in the pathway (Figure 3 ). One example is the serum-derived endogenous factor C1-INH (Berinert, Cinryze, NCT02547220; ref. 110). Alternatively, an anti-C1s antibody is in clinical trials for the treatment of complement-mediated diseases (NCTO2502903). Since the capacity of IgG to activate complement depends on interaction with $\mathrm{C} 1 \mathrm{q}$ via the glycosylated $\mathrm{CH} 2$ domain in the $\mathrm{Fc}$ region, other possible therapies to attenuate complementmediated injury include the Staphylococcus aureus enzymes IdeS and EndoS (111-113). These enzymes cause cleavage of the Fc tail (IdeS) or of the N-linked glycan (EndoS) and abolish complement activation in animal models of antibody-mediated inflammation (111-114). Clinical trials for desensitization with IdeS are currently under way in Europe and the United States (NCT02426684); however, such approaches are likely to be limited because of (a) risk of allergic reaction due to antibody responses against these bacterial enzymes, and (b) reconstitution of circulating IgG, which occurs in 2-3 weeks. Fc inactivation could be a salvage therapy, but likely needs to be combined with effective $B$ cell depletion for durable protection of the allograft from DSAs.

In summary, complement activation in the allograft can be detected by immunohistochemistry for $\mathrm{C} 4 \mathrm{~d}$, which is an important but not universal feature of AMR. Several established and emerging therapeutics exist for antagonism of complement activation in transplant recipients, but they do not represent a "silver bullet," since there are concurrent, non-complement-mediated mechanisms of allograft injury triggered by HLA antibodies.

\section{Intravascular mononuclear cells}

Diagnosis. Another key characteristic of AMR across solid organs is the presence of intracapillary mononuclear cells (leukocytes) in the allograft (Figure 2). While larger vessels may be affected in more severe cases of AMR ("arteritis" or "vasculitis"; ref. 42), capillary dilatation with inflammatory cell margination with characteristic linear staining is a key feature of AMR. Staining for the macrophage marker CD68 has been shown to be informative for diagnosis of AMR in cardiac allografts (115). Although not included in the diagnostic criteria, increased glomerular macrophage burden correlates with AMR in renal allografts and is a histological feature of acute tissue injury in AMR with or without C4d deposition (30, $116,117)$. The utility of CD68 staining in lung and liver is questionable. Rather AMR is characterized by a monocytic, neutrophilic, or eosinophilic infiltrate in these organs $(31,33,95,118)$, again with inflammatory cells adherent to microvascular endothelial cells.

Growing evidence in human and murine transplantation shows that other leukocyte subsets play an important role in AMR. $\mathrm{T}$ lymphocytes may also be found in allografts undergoing AMR 
(119). Infiltrating B cells form ectopic lymphoid structures within the allograft and locally secrete HLA antibodies $(120,121)$. NK cells and their associated transcripts are increased in human renal, cardiac, and lung allografts during AMR (122-126) and mediate acute and chronic AMR in mouse transplant models (127-130).

Mechanisms and therapies. In vitro, HLA I antibodies mobilize endothelial vesicles called Weibel-Palade bodies, externalizing the adhesion molecule P-selectin $(131,132)$. Cell surface P-selectin expression by endothelial cells in turn supports adhesion of platelets (133), neutrophils (132), and monocytes (131) in vitro and in vivo, which likely contributes to the infiltration of recipient immune cells. Interactions between endothelial-bound IgG and myeloid cell Fc $\gamma$ Rs can facilitate tethering and adhesion of leukocytes in autoimmune inflammation (134) and in response to HLA antibodies (refs. 135,136 , and Figure 2). Active complement-mediated inflammation also promotes recruitment of $\mathrm{T}$ cells, monocytes, and neutrophils via direct chemotactic effects on immune cells, and by amplifying endothelial cell activation (104). Intragraft macrophages have a proinflammatory phenotype during acute rejection, and a repair/ profibrotic phenotype during chronic rejection (137), suggesting that macrophage effector functions differentially contribute to acute and chronic AMR.

NK cells express one receptor for IgG, Fc $\gamma$ RIIIA (CD16a), which facilitates antibody-dependent cell-mediated cytotoxicity against target cells. Stimulation of NK cells through Fc $\gamma$ RIIIA increased expression of a number of proinflammatory genes in vitro that were also validated in biopsies from human renal (138) and heart allografts (124) undergoing AMR. IFN- $\gamma$ production by NK cells can be triggered by allogeneic target cells coated with alloantibody (139), and contributes to chronic rejection in murine models (129). Current immunosuppressive drugs incompletely inhibit NK cell-mediated alloreactivity (140).

There are currently no therapies directly aimed at preventing recruitment or function of allograft infiltrating leukocytes. It is possible that treatment of DSA-positive patients with IdeS and/ or EndoS to cleave the Fc region of circulating IgG might be efficacious in reducing $\mathrm{Fc} \gamma \mathrm{R}$-mediated monocyte recruitment into the allograft (ref. 136 and Figure 3), but this application has yet to be tested in the clinic. Although we can conjecture from findings in other disease models, it is not clear exactly what intravascular macrophages, NK cells, and neutrophils are doing in the allograft that contributes to injury. Moreover, the interrelated mechanisms, including additive effects, mutual regulation, and feedback, of these distinct leukocyte subsets are a complex and fascinating issue that remains to be elucidated. Consequently, the functions of such innate immune cells, and how they interweave, may represent new targets of immunosuppressive therapy to treat AMR.

\section{Microvascular inflammation and endothelial injury}

Diagnosis. Donor endothelial cells are in direct contact with the recipient immune system and are the predominant target of the alloimmune response. AMR typically manifests in the microvasculature of the transplanted organ. Microvascular inflammation appears as endothelial cell or cytoplasmic swelling or enlargement and vacuolization. In cardiac allografts, staining of endothelial cells with CD31 highlights capillaries with endothelial dilation, nuclear enlargement, or "swelling" $(29,115)$. In the lung, capillary inflammation was associated with HLA DSAs (96), and in liver, endothelial cell hypertrophy and dilatation are noted in the peribiliary capillaries and portal microvasculature (31).

HLA antibodies promote activation of intracellular signaling in vitro and in animal models (141-147). Several studies have demonstrated that detection of phosphorylated signaling molecules that are activated downstream of HLA cross-linking, including S6 ribosomal protein and S6 kinase, aids in detection of AMR in cardiac allografts $(101,102,148)$. Sis and colleagues first reported that rejecting renal transplants exhibit increased expression of endothelial-associated transcripts $(149,150)$, a finding that has been further substantiated by the same group in cardiac allografts $(124,151)$. Thus, the "molecular microscope" may enable pathologists to further distinguish AMR from other forms of allograft injury (152), and facilitate a better understanding of intragraft changes during AMR, but the field awaits confirmation of these studies by other laboratories.

Mechanisms and therapies. Endothelial cell injury and activation lie at the heart of antibody-mediated allograft damage. Extensive in vitro evidence points to an intrinsic role for HLA signaling within the graft vasculature that promotes angiogenic and inflammatory responses (Figure 2). For example, cross-linking of HLA class I with bivalent antibodies mimics trans interactions with $\mathrm{T}$ cell receptors, triggering phosphorylation of Src and focal adhesion kinases (FAKs), mTOR, ERK, and S6 ribosomal protein in endothelial and smooth muscle cells $(143,145,146)$. These signaling pathways promote cytoskeletal rearrangements, as well as increased wound healing and cell growth $(143,145,146)$. Activation of these signaling molecules during AMR has been substantiated in vivo in a murine model (147) as well as in human cardiac allografts $(101,102)$. Much less is known about the signaling events in endothelium after HLA II cross-linking. This is a significant gap in our knowledge, since numerous studies have found a strong relationship between DSAs against HLA-DQ and chronic rejection. Exposure of HLA-DR-expressing endothelial cells increased ERK and Akt phosphorylation (153), as well as activation of proinflammatory Th17 cells (154). More studies are needed to elucidate the effect of antibodies against HLA II on vascular endothelial cell signaling, and how they contribute to acute and chronic AMR.

Currently, no treatments exist to directly modulate graft vascular function. However, given what is known from experimental models and clinical studies, the mTOR signaling axis is activated by HLA antibodies and represents a viable therapeutic target to dampen endothelial cell activation during AMR (Figure 3).

\section{Allograft dysfunction}

AMR manifests as a broad spectrum both histologically and symptomatically. Certainly, AMR identified on for-cause biopsies concomitant with overt allograft dysfunction warrants treatment. Patients who experience clinically symptomatic AMR and severe AMR have significantly worse long-term outcomes compared with stable patients or those experiencing other forms of rejection, such as acute cell-mediated rejection (155). However, patients may also have detectable circulating DSAs but no histological rejection or allograft dysfunction. In other cases, DSAs may be present with subtle changes on biopsy, but no impairment of function. 
Table 2. The features of transplant vasculopathy across solid organs and composite tissue allografts

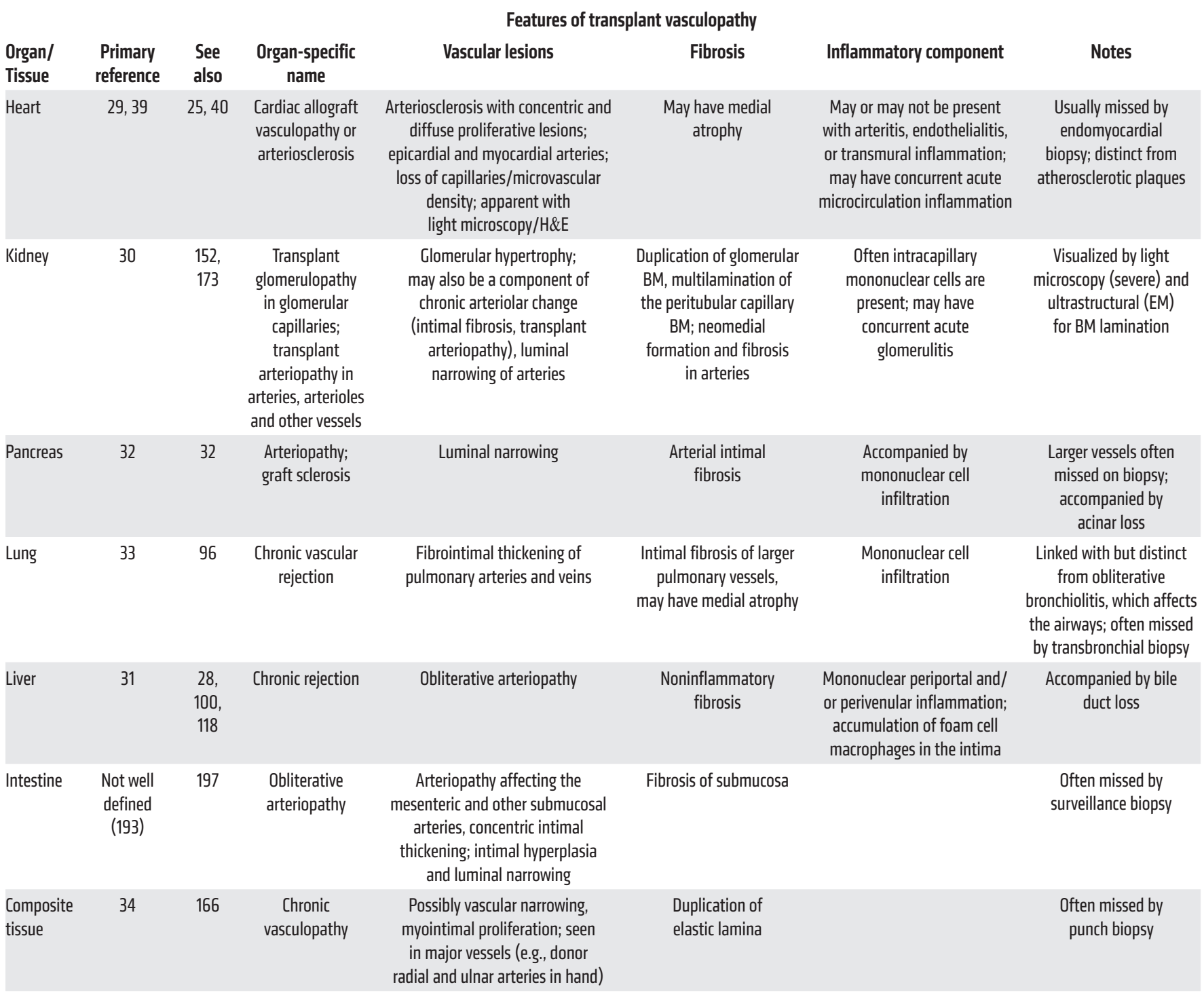

Note that chronic AMR is a distinct diagnosis that is often concurrent with transplant vasculopathy. BM, basement membrane; EM, electron microscopy.

Rush et al. first noted subclinical AMR in protocol renal allograft biopsies (156), and subsequently there has been increased appreciation that patients without overt graft dysfunction may exhibit abnormal histology on biopsy of renal $(6,43,157)$, cardiac $(155,158)$, and liver (159) allografts. For example, among patients who developed dnDSAs but had stable allograft function, 25\% exhibited acute subclinical AMR and 7.5\% had chronic AMR on surveillance biopsy (3). One year after dnDSA appearance, these patients had further increased incidence of AMR (3). Importantly, patients with subclinical AMR experience faster rates of allograft function decline, higher incidence of transplant vasculopathy (TV), and greater risk of graft loss $(6,21,43,160)$, falling at intermediate risk for graft failure between those without DSAs or dysfunction and those with clinically symptomatic AMR.

Patients treated with plasmapheresis for subclinical AMR had no significant difference in their risk of graft loss at 5 years com- pared with when subclinical AMR was left untreated (21). Taken together, these studies provide compelling evidence that patients with DSAs but without overt clinical dysfunction are at higher risk for graft loss compared with their DSA-negative counterparts. Intervention is therefore warranted, particularly when AMR is severe (161), but current therapies do not appear efficacious to improve long-term outcomes.

\section{Manifestations and mechanisms of chronic AMR and TV}

Incidence and clinical impact. Repeated injury of the graft vasculature and uncontrolled repair responses contribute to chronic rejection $(25,162)$ that, in many cases, progresses to TV. Thirty percent of heart transplant recipients are diagnosed with TV by 5 years after transplant, and $50 \%$ by 10 years after transplant (163). TV is a leading cause of retransplantation. While nonim- 
mune factors also contribute to TV, the majority of renal allograft loss due to chronic rejection was associated with HLA DSAs (24, 164). Chronic rejection is also an important cause of late failure of vascularized CTA $(165,166)$. Similarly, chronic damage and TV in heart $(25)$, lung $(95,167,168)$, pancreas $(169)$, and liver $(11,28$, 170) allografts are more common among patients with a history of biopsy-proven AMR and HLA DSAs.

Only half of renal allografts were functioning within 18 months of diagnosis of chronic AMR (164). Median survival time of lung allografts after diagnosis of bronchiolitis obliterans syndrome (BOS) is less than 3 years (171). TV accounts for one-third of cardiac allograft recipient deaths late after transplant (163). Therefore, chronic rejection culminating in TV is currently an irreversible process with significant impact on patient morbidity and mortality.

Chronic AMR occurs late (more than 1 year) after transplant but exhibits many of the features characteristic of acute AMR in each organ, including endothelial cell changes, microvascular inflammation, $\mathrm{C} 4 \mathrm{~d}$, and circulating donor-specific antibodies. In addition, fibrosis is an important characteristic of chronic AMR $(31,172)$. For example, transplant glomerulopathy is a feature of chronic AMR in renal allografts, with duplication of the basement membrane in the glomerulus and peritubular capillaries (173).

Allografts with TV suffer from neointimal expansion and fibrosis in the larger vessels, which is largely considered a manifestation or consequence of chronic AMR. TV may be missed on routine biopsy owing to its predominant involvement of larger vessels that are not often observed except on deep tissue samples. For example, in the heart, cardiac allograft vasculopathy (CAV) is detected by imaging such as intravascular ultrasound or histologically only upon explant. CAV appears as arteriosclerotic lesions with inflammatory neointimal hyperplasia that can be clearly distinguished from eccentric atherosclerotic plaques (25). Intimal thickening may be so severe as to fully occlude the affected vasculature. Similarly, arteriopathy of kidney transplants is a consequence of intimal fibrosis and expansion in the renal arteries. An overview of the features of TV across organs and CTA is provided in Table 2.

Mechanisms and therapies. Although clinical evidence strongly supports the association between chronic AMR, TV, and HLA DSAs in numerous solid organs, the precise mechanisms by which neointimal proliferation and fibrosis occur are unclear. In part, this is because it is difficult to model this process in vitro, and there has been a historical lack of an appropriate animal model. Multiple other mechanisms contribute to TV, including chronic T cell-mediated injury and viral and/or metabolic risk factors, but HLA antibodies are both a major risk factor and a probable causative agent for chronic vascular changes. Our group and others have demonstrated in in vitro models that HLA antibodies trigger prosurvival and proliferative intracellular signaling via ERK and mTOR in vascular endothelial and smooth muscle cells, promoting growth, cytoskeletal changes, and migration (131, 141-147). Phosphorylation of these signaling molecules has been substantiated in AMR in both mouse and human allografts $(102,147,148)$. HLA I antibodies also elicit matrix metalloprotease- and sphingolipidmediated signaling in vascular smooth muscle cells, which are thought to contribute to the intimal hyperplasia seen in TV (174,
175). Antibodies, NK cells, and complement likely promote endothelial apoptosis, enhancing leukocyte adhesion, matrix remodeling and fibrosis, and thrombosis (176). Indeed, in early TV, coronary artery endothelia exhibited apoptotic phenotypes (177). New evidence shows that apoptotic endothelial microparticles are increased in renal transplant recipients with AMR (178), in cardiac allograft recipients with CAV (179), and in lung recipients with BOS (180). Such graft-derived exosomes and microvesicles might represent an important marker of graft damage, as well as a potential source of alloantigen.

Endothelial cells exposed to HLA antibodies also elaborate IL-8, TNF- $\alpha$ (181), and VEGF (182), which can signal in an autocrine fashion or act on smooth muscle cells in a paracrine manner. Complement activation at the endothelial surface can enhance these processes leading to intimal expansion by acting directly on endothelial cells and augmenting adhesion of leukocytes (104), although in murine models complement deficiency did not impact TV (127).

In vivo studies using $\mathrm{T}$ cell- and $\mathrm{B}$ cell-deficient murine recipients passively transferred with anti-donor MHC I antibodies demonstrated that DSAs triggered vascular lesions in cardiac allografts reminiscent of TV in humans $(127,129)$. This model has identified a key role for NK cells, IFN- $\gamma$, and Fas/FasLmediated injury in the process of DSA-induced TV $(127,183)$. An alternative model using passive transfer of anti-HLA antibodies and human $\mathrm{T}$ cells into murine recipients of human arterial grafts demonstrated that $\mathrm{CD} 4^{+} \mathrm{T}$ cells also infiltrate the neointima and produce IFN- $\gamma(104)$.

No treatment options reverse TV once established. Use of statins is encouraged because of a substantial survival benefit and significantly lower incidence of CAV $(184,185)$. In addition, mTOR inhibitors reduce neointimal thickening in animal models and in human transplantation (186-188). This is likely partly attributable to general antiproliferative properties, since mTOR inhibitors also reduce neointimal hyperplasia in other vascular injury models (189). We have proposed that mTOR inhibition may also ameliorate progrowth signaling in the vasculature triggered by HLA antibodies (143). Recently, antibody-mediated TV in murine recipients capable of mounting a de novo antibody response against renal allografts was reported (190). This breakthrough holds promise to elucidate the physiological processes driving chronic allograft injury by alloantibodies, including the independent and interrelated contributions of complement, endothelial signaling, and different leukocyte subsets.

\section{Conclusions}

The mechanisms of HLA antibody-mediated allograft injury are manifold, and manifest as universal histological features across all transplanted solid organs. AMR is characterized by circulating DSAs or non-HLA antibodies, evidence of complement deposition, microvascular inflammation with leukocyte infiltration, and endothelial injury. Repeated injury of the allograft culminates in TV, with fibrosis and neointimal expansion in larger vessels. The arsenal of therapies to combat AMR and chronic rejection is growing, but today's treatments do not address all of the components of antibody-mediated injury. In particular, the intracellular signaling pathways leading to endo- 
thelial dysfunction and recruitment of leukocytes have yet to be effectively targeted. AMR also presents as a continuum of histological and clinical features. Advancing toward precision medicine in transplantation will require an understanding that each patient may need a different, combinatorial approach to prevent and alleviate AMR. Along these lines, improving the organ allocation system to favor HLA or HLA epitope matching or avoiding specific epitope mismatches that are highly immunogenic holds promise to reduce allosensitization and improve graft and patient outcomes (191). This strategy would be particularly useful in children, who will likely require two or more transplants during their lifetime.

\section{Acknowledgments}

This work was supported by NIH grant RO1AI42819 (to EFR). The authors gratefully extend their thanks to W. Dean Wallace (UCLA Department of Pathology and Laboratory Medicine) for critical review of the manuscript and for providing the micrographs of allograft histology in Figure 2.

Address correspondence to: Elaine F. Reed, UCLA Immunogenetics Center, Department of Pathology and Laboratory Medicine, David Geffen School of Medicine, University of California Los Angeles, 1000 Veteran Avenue, Los Angeles, California 90095, USA. Phone: 310.794.4943; Email: ereed@mednet.ucla.edu.
1. Hart A, et al. OPTN/SRTR 2015 Annual Data Report: Kidney. Am J Transplant. 2017;17(suppl 1):21-116.

2. Patel R, Terasaki PI. Significance of the positive crossmatch test in kidney transplantation. $N$ Engl JMed. 1969;280(14):735-739.

3. Schinstock CA, et al. The value of protocol biopsies to identify patients with de novo donorspecific antibody at high risk for allograft loss [published online ahead of print December 15, 2016]. Am J Transplant. https://doi.org/ 10.1111/ajt.14161.

4. Everly MJ, et al. Incidence and impact of de novo donor-specific alloantibody in primary renal allografts. Transplantation. 2013;95(3):410-417.

5 . Viglietti D, et al. Value of donor-specific antiHLA antibody monitoring and characterization for risk stratification of kidney allograft loss. JAm Soc Nephrol. 2017;28(2):702-715.

6 . Wiebe C, et al. Rates and determinants of progression to graft failure in kidney allograft recipients with de novo donor-specific antibody. Am J Transplant. 2015;15(11):2921-2930.

7. Comoli P, et al. Acquisition of C3d-binding activity by de novo donor-specific HLA antibodies correlates with graft loss in nonsensitized pediatric kidney recipients. Am J Transplant. 2016;16(7):2106-2116.

8. Tran A, Fixler D, Huang R, Meza T, Lacelle C Das BB. Donor-specific HLA alloantibodies: impact on cardiac allograft vasculopathy, rejection, and survival after pediatric heart transplantation. J Heart Lung Transplant. 2016;35(1):87-91.

9. Smith JD, et al. De novo donor HLA-specific antibodies after heart transplantation are an independent predictor of poor patient survival. Am J Transplant. 2011;11(2):312-319.

10. Morrell MR, et al. De novo donor-specific HLA antibodies are associated with early and highgrade bronchiolitis obliterans syndrome and death after lung transplantation. J Heart Lung Transplant. 2014;33(12):1288-1294.

11. Kaneku H, et al. De novo donor-specific HLA antibodies decrease patient and graft survival in liver transplant recipients. Am J Transplant. 2013;13(6):1541-1548

12. Cheng EY, et al. Prevalence and clinical impact of donor-specific alloantibody among intestinal transplant recipients. Transplantation. 2017;101(4):873-882.

13. Alba AC, et al. Factors associated with antihuman leukocyte antigen antibodies in patients supported with continuous-flow devices and effect on probability of transplant and posttransplant outcomes. J Heart Lung Transplant. 2015;34(5):685-692.

14. Amico P, et al. Risk stratification by the virtual crossmatch: a prospective study in 233 renal transplantations. Transpl Int. 2011;24(6):560-569.

15. Amrouche L, et al. Long-term outcomes of kidney transplantation in patients with high levels of preformed DSA: the Necker high-risk transplant program [published online ahead of print January 21, 2017]. Transplantation. https://doi. org/10.1097/TP.0000000000001650.

16. Askar M, et al. HLA and MICA allosensitization patterns among patients supported by ventricular assist devices. J Heart Lung Transplant. 2013;32(12):1241-1248.

17. Bielmann D, Hönger G, Lutz D, Mihatsch MJ, Steiger J, Schaub S. Pretransplant risk assessment in renal allograft recipients using virtual crossmatching. Am J Transplant. 2007;7(3):626-632.

18. Haas M, et al. Subclinical acute antibodymediated rejection in positive crossmatch renal allografts. Am J Transplant. 2007;7(3):576-585.

19. Irving CA, et al. Effect of persistent versus transient donor-specific HLA antibodies on graft outcomes in pediatric cardiac transplantation. J Heart Lung Transplant. 2015;34(10):1310-1317.

20. Loupy A, et al. Complement-binding anti-HLA antibodies and kidney-allograft survival. $N$ EnglJ Med. 2013;369(13):1215-1226.

21. Orandi BJ, et al. Quantifying renal allograft loss following early antibody-mediated rejection. Am J Transplant. 2015;15(2):489-498.

22. Roux A, et al. Antibody-mediated rejection in lung transplantation: clinical outcomes and donor-specific antibody characteristics. Am J Transplant. 2016;16(4):1216-1228.

23. Lefaucheur C, et al. Determinants of poor graft outcome in patients with antibody-mediated acute rejection. Am J Transplant. 2007;7(4):832-841.

24. Einecke G, et al. Antibody-mediated microcirculation injury is the major cause of late kidney transplant failure. Am J Transplant. 2009;9(11):2520-2531.

25. Loupy A, et al. Late failing heart allografts: pathology of cardiac allograft vasculopathy and association with antibody-mediated rejection. Am J Transplant. 2016;16(1):111-120.

26. de Kort H, et al. Pancreas allograft biopsies with positive $\mathrm{c} 4 \mathrm{~d}$ staining and anti-donor antibodies related to worse outcome for patients. $\mathrm{Am} \mathrm{J}$
Transplant. 2010;10(7):1660-1667.

27. Iacob S, et al. Donor-specific anti-HLA antibodies and endothelial C4d deposition-association with chronic liver allograft failure. Transplantation. 2015;99(9):1869-1875.

28. Wozniak LJ, et al. Donor-specific HLA antibodies are associated with late allograft dysfunction after pediatric liver transplantation. Transplantation. 2015;99(7):1416-1422.

29. Berry GJ, et al. The 2013 International Society for Heart and Lung Transplantation Working Formulation for the standardization of nomenclature in the pathologic diagnosis of antibodymediated rejection in heart transplantation. J Heart Lung Transplant. 2013;32(12):1147-1162.

30. Haas M, et al. Banff 2013 meeting report: inclusion of C4d-negative antibody-mediated rejection and antibody-associated arterial lesions. Am J Transplant. 2014;14(2):272-283.

31. Demetris AJ, et al. 2016 Comprehensive Update of the Banff Working Group on Liver Allograft Pathology: Introduction of Antibody-Mediated Rejection [published online ahead of print June 7, 2016]. Am J Transplant. https://doi.org/ 10.1111/ajt.13909.

32. Drachenberg CB, et al. Guidelines for the diagnosis of antibody-mediated rejection in pancreas allografts-updated Banff grading schema. Am J Transplant. 2011;11(9):1792-1802.

33. Levine DJ, et al. Antibody-mediated rejection of the lung: a consensus report of the International Society for Heart and Lung Transplantation. J Heart Lung Transplant. 2016;35(4):397-406.

34. Cendales LC, et al. The Banff 2007 working classification of skin-containing composite tissue allograft pathology. Am J Transplant. 2008;8(7):1396-1400.

35. Wu GS, Cruz RJ Jr, Cai JC. Acute antibodymediated rejection after intestinal transplantation. World J Transplant. 2016;6(4):719-728.

36. Philogene MC, et al. Anti-angiotensin II type 1 receptor and anti-endothelial cell antibodies: a cross-sectional analysis of pathological findings in allograft biopsies. Transplantation. 2017;101(3):608-615.

37. Reinsmoen NL, et al. A 3 center study reveals new insights into the impact of nonHLA antibodies on lung transplantation outcome. Transplantation. 2017;101(6):1215-1221.

38. Gerlach UA, et al. Non-HLA antibodies may accelerate immune responses after intestinal and multivisceral transplantation. Transplantation. 
2017;101(1):141-149.

39. Berry GJ, et al. The ISHLT working formulation for pathologic diagnosis of antibody-mediated rejection in heart transplantation: evolution and current status (2005-2011). JHeart Lung Transplant. 2011;30(6):601-611.

40. Bruneval P, et al. The XIIIth Banff conference on Allograft Pathology: The Banff 2015 Heart Meeting Report: Improving Antibody-Mediated Rejection Diagnostics: Strengths, Unmet Needs, and Future Directions. Am J Transplant. 2017;17(1):42-53.

41. Vlad G, et al. Relevance of different antibody detection methods for the prediction of antibody-mediated rejection and deceaseddonor kidney allograft survival. Hum Immunol. 2009;70(8):589-594.

42. Lefaucheur C, et al. Antibody-mediated vascular rejection of kidney allografts: a population-based study. Lancet. 2013;381(9863):313-319.

43. Loupy A, et al. Subclinical rejection phenotypes at 1 year post-transplant and outcome of kidney allografts. J Am Soc Nephrol. 2015;26(7):1721-1731.

44. Zeevi A, et al. Persistent strong anti-HLA antibody at high titer is complement binding and associated with increased risk of antibodymediated rejection in heart transplant recipients. J Heart Lung Transplant. 2013;32(1):98-105.

45. Chin C, et al. Clinical usefulness of a novel C1q assay to detect immunoglobulin $\mathrm{G}$ antibodies capable of fixing complement in sensitized pediatric heart transplant patients. J Heart Lung Transplant. 2011;30(2):158-163.

46. Sicard A, et al. Detection of C3d-binding donor-specific anti-HLA antibodies at diagnosis of humoral rejection predicts renal graft loss. JAm Soc Nephrol. 2015;26(2):457-467.

47. Smith JD, Hamour IM, Banner NR, Rose ML. C4d fixing, luminex binding antibodies - a new tool for prediction of graft failure after heart transplantation. Am J Transplant. 2007;7(12):2809-2815.

48. Wahrmann M, et al. Clinical relevance of preformed C4d-fixing and non-C4d-fixing HLA single antigen reactivity in renal allograft recipients. Transpl Int. 2009;22(10):982-989.

49. Guidicelli G, et al. Non-complement-binding de novo donor-specific anti-HLA antibodies and kidney allograft survival. J Am Soc Nephrol. 2016;27(2):615-625.

50. Rogiers X, Berrevoet F, Troisi R. Comments on Bonney et al. "Outcomes on right liver lobe transplantation: a match pair analysis" (Transpl. Int. 2008; 21: 1045-1051). Transpl Int. 2009;22(5):588.

51. Viglietti D, Lefaucheur C, Glotz D. Evidence for an important role of both complement-binding and noncomplement-binding donor-specific antibodies in renal transplantation. Curr Opin Organ Transplant. 2016;21(4):433-440.

52. Wiebe $\mathrm{C}$, et al. Evaluation of $\mathrm{C} 1 \mathrm{q}$ status and titer of de novo donor-specific antibodies as predictors of allograft survival. Am J Transplant. 2017;17(3):703-711.

53. Claisse G, Absi L, Cognasse F, Alamartine E, Mariat C, Maillard N. Relationship between Mean Fluorescence Intensity and C1q/C3dfixing capacities of anti-HLA antibodies. Hum Immunol. 2017;78(4):336-341.

54. Yell M, Muth BL, Kaufman DB, Djamali A, Ellis
TM. C1q binding activity of de novo donorspecific HLA antibodies in renal transplant recipients with and without antibody-mediated rejection. Transplantation. 2015;99(6):1151-1155.

55. Arnold ML, Ntokou IS, Doxiadis II, Spriewald BM, Boletis JN, Iniotaki AG. Donor-specific HLA antibodies: evaluating the risk for graft loss in renal transplant recipients with isotype switch from complement fixing IgG1/IgG3 to noncomplement fixing IgG2/IgG4 anti-HLA alloantibodies. Transpl Int. 2014;27(3):253-261.

56. Cicciarelli JC, et al. Immunoglobulin $\mathrm{G}$ subclass analysis of HLA donor specific antibodies in heart and renal transplant recipients. Clin Transpl. 2013;2013:413-422.

57. Freitas MC, et al. The role of immunoglobulin- $G$ subclasses and C1q in de novo HLA-DQ donor-specific antibody kidney transplantation outcomes. Transplantation. 2013;95(9):1113-1119.

58. Khovanova N, et al. Subclass analysis of donor HLA-specific IgG in antibody-incompatible renal transplantation reveals a significant association of IgG4 with rejection and graft failure. Transpl Int. 2015;28(12):1405-1415.

59. Lefaucheur C, et al. IgG donor-specific antihuman HLA antibody subclasses and kidney allograft antibody-mediated injury. JAm Soc Nephrol. 2016;27(1):293-304.

60. Hönger G, Hopfer H, Arnold ML, Spriewald BM, Schaub S, Amico P. Pretransplant IgG subclasses of donor-specific human leukocyte antigen antibodies and development of antibody-mediated rejection. Transplantation. 2011;92(1):41-47.

61. Morales-Buenrostro LE, Terasaki PI, MarinoVázquez LA, Lee JH, El-Awar N, Alberú J. “Natural" human leukocyte antigen antibodies found in nonalloimmunized healthy males. Transplantation. 2008;86(8):1111-1115.

62. Sicard A, et al. Outcome of kidney transplantations performed with preformed donor-specific antibodies of unknown etiology. Am J Transplant. 2014;14(1):193-201.

63. Heidt S, et al. A NOVel ELISPOT assay to quantify HLA-specific B cells in HLA-immunized individuals. Am J Transplant. 2012;12(6):1469-1478.

64. Lúcia M, et al. Preformed circulating HLA-specific memory B cells predict high risk of humoral rejection in kidney transplantation. Kidney Int . 2015;88(4):874-887.

65. Han M, Rogers JA, Lavingia B, Stastny P. Peripheral blood $\mathrm{B}$ cells producing donorspecific HLA antibodies in vitro. Hum Immunol. 2009;70(1):29-34.

66. Snanoudj R, Claas FH, Heidt S, Legendre C, Chatenoud L, Candon S. Restricted specificity of peripheral alloreactive memory B cells in HLA-sensitized patients awaiting a kidney transplant. Kidney Int. 2015;87(6):1230-1240.

67. Lucas DP, Leffell MS, Zachary AA. Tetramer staining for the detection of HLA-specific B cells. Methods Mol Biol. 2013;1034:313-318.

68. Pizzo HP, et al. Sirolimus and tacrolimus coefficient of variation is associated with rejection, donor-specific antibodies, and nonadherence. Pediatr Nephrol. 2016;31(12):2345-2352.

69. Yang J, et al. Tracing donor-MHC Class II reactive $\mathrm{B}$ cells in mouse cardiac transplantation: delayed CTLA4-Ig treatment prevents memory alloreactive B-cell generation. Transplantation. 2016;100(8):1683-1691.

70. Young JS, et al. Delayed cytotoxic T lymphocyteassociated protein 4 -immunoglobulin treatment reverses ongoing alloantibody responses and rescues allografts from acute rejection. Am J Transplant. 2016;16(8):2312-2323.

71. Rostaing L, et al. Long-term belatacept exposure maintains efficacy and safety at 5 years: results from the long-term extension of the BENEFIT study. Am J Transplant. 2013;13(11):2875-2883.

72. Durandy A, et al. Intravenous immunoglobulins - understanding properties and mechanisms. Clin Exp Immunol. 2009;158(suppl 1):2-13.

73. Sautenet B, et al. One-year results of the effects of Rituximab on acute antibody-mediated rejection in renal transplantation: RITUX ERAH, a multicenter double-blind randomized placebo-controlled trial. Transplantation. 2016;100(2):391-399.

74. Vo AA, et al. Rituximab and intravenous immune globulin for desensitization during renal transplantation. NEngl J Med. 2008;359(3):242-251.

75. Bingham CO, et al. Immunization responses in rheumatoid arthritis patients treated with rituximab: results from a controlled clinical trial. Arthritis Rheum. 2010;62(1):64-74.

76. Woodle ES, et al. Prospective iterative trial of proteasome inhibitor-based desensitization. Am J Transplant. 2015;15(1):101-118.

77. Kuhn DJ, et al. Potent activity of carfilzomib, a novel, irreversible inhibitor of the ubiquitin-proteasome pathway, against preclinical models of multiple myeloma. Blood.2007;110(9):3281-3290.

78. Sberro-Soussan R, et al. Bortezomib as the sole post-renal transplantation desensitization agent does not decrease donor-specific anti-HLA antibodies. Am J Transplant. 2010;10(3):681-686.

79. Stegall MD, Gloor J, Winters JL, Moore SB, Degoey $\mathrm{S}$. A comparison of plasmapheresis versus high-dose IVIG desensitization in renal allograft recipients with high levels of donor specific alloantibody. Am J Transplant. 2006;6(2):346-351.

80. Mai ML, et al. Excellent renal allograft survival in donor-specific antibody positive transplant patients-role of intravenous immunoglobulin and rabbit antithymocyte globulin. Transplantation. 2009;87(2):227-232.

81. Kobashigawa JA, et al. The long-term outcome of treated sensitized patients who undergo heart transplantation. Clin Transplant. 2011;25(1):E61-E67.

82. Mujtaba MA, et al. Effect of treatment with tabalumab, a B cell-activating factor inhibitor, on highly sensitized patients with end-stage renal disease awaiting transplantation. Am J Transplant. 2016;16(4):1266-1275.

83. Banham G, et al. Elevated pretransplantation soluble BAFF is associated with an increased risk of acute antibody-mediated rejection. Transplantation. 2013;96(4):413-420.

84. Snanoudj R, et al. Peripheral B-cell phenotype and BAFF levels are associated with HLA immunization in patients awaiting kidney transplantation. Transplantation. 2014;97(9):917-924.

85. Sango C, et al. B-cell-activating factor levels are associated with antibody-mediated histological damage in kidney transplantation. Transplant Proc. 2016;48(9):2910-2912. 
86. Kwun J, et al. Neutralizing BAFF/APRIL with atacicept prevents early DSA formation and AMR development in T cell depletion induced nonhuman primate AMR model. Am J Transplant. 2015;15(3):815-822.

87. Navarra SV, et al. Efficacy and safety of belimumab in patients with active systemic lupus erythematosus: a randomised, placebo-controlled, phase 3 trial. Lancet. 2011;377(9767):721-731.

88. Vo AA, et al. A phase I/II trial of the interleukin-6 receptor-specific humanized monoclonal (Tocilizumab) + intravenous immunoglobulin in difficult to desensitize patients. Transplantation. 2015;99(11):2356-2363.

89. Choi J, et al. Assessment of Tocilizumab (antiIL-6 receptor monoclonal) as a potential treatment for chronic antibody mediated rejection transplant glomerulopathy in HLA sensitized renal allograft recipients [published online ahead of print February 17, 2017]. Am J Transplant. https://doi.org/10.1111/ajt.14228.

90. Rizzi M, et al. Impact of tofacitinib treatment on human B-cells in vitro and in vivo. J Autoimmun. 2017;77:55-66.

91. Vincenti F, et al. Evaluation of the effect of tofacitinib exposure on outcomes in kidney transplant patients. Am J Transplant. 2015;15(6):1644-1653.

92. Moore CA, et al. Janus kinase inhibition for immunosuppression in solid organ transplantation: Is there a role in complex immunologic challenges? Hum Immunol. 2017;78(2):64-71.

93. Collins AB, et al. Complement activation in acute humoral renal allograft rejection: diagnostic significance of $\mathrm{C} 4 \mathrm{~d}$ deposits in peritubular capillaries. J Am Soc Nephrol. 1999;10(10):2208-2214.

94. Feucht HE, et al. Capillary deposition of C4d complement fragment and early renal graft loss. Kidney Int. 1993;43(6):1333-1338.

95. DeNicola MM, Weigt SS, Belperio JA, Reed EF, Ross DJ, Wallace WD. Pathologic findings in lung allografts with anti-HLA antibodies. J Heart Lung Transplant. 2013;32(3):326-332.

96. Wallace WD, et al. Banff study of pathologic changes in lung allograft biopsy specimens with donor-specific antibodies. J Heart Lung Transplant. 2016;35(1):40-48.

97. Yousem SA, Zeevi A. The histopathology of lung allograft dysfunction associated with the development of donor-specific HLA alloantibodies. Am J Surg Pathol. 2012;36(7):987-992.

98. Bellamy CO. Complement C4d immunohistochemistry in the assessment of liver allograft biopsy samples: applications and pitfalls. Liver Transpl. 2011;17(7):747-750.

99. Kanitakis J, et al. Absence of c4d deposition in human composite tissue (hands and face) allograft biopsies: an immunoperoxidase study. Transplantation. 2007;84(2):265-267.

100.Lunz J, et al. Re-examination of the lymphocytotoxic crossmatch in liver transplantation: can C4d stains help in monitoring? Am J Transplant. 2012;12(1):171-182.

101.Li F, et al. Phosphorylated S6 kinase and S6 ribosomal protein are diagnostic markers of antibody-mediated rejection in heart allografts. J Heart Lung Transplant. 2015;34(4):580-587.

102. Tible M, et al. Pathologic classification of antibody-mediated rejection correlates with donor-specific antibodies and endothelial cell activation. J Heart Lung Transplant. 2013;32(8):769-776.

103. Orandi BJ, et al. Presentation and outcomes of C4d-negative antibody-mediated rejection after kidney transplantation. Am J Transplant. 2016;16(1):213-220.

104.Jane-Wit D, et al. Alloantibody and complement promote $\mathrm{T}$ cell-mediated cardiac allograft vasculopathy through noncanonical nuclear factor$\kappa \mathrm{B}$ signaling in endothelial cells. Circulation. 2013;128(23):2504-2516.

105. Foreman KE, Glovsky MM, Warner RL, Horvath SJ, Ward PA. Comparative effect of C3a and $\mathrm{C} 5 \mathrm{a}$ on adhesion molecule expression on neutrophils and endothelial cells. Inflammation. 1996;20(1):1-9.

106.Stegall MD, et al. Terminal complement inhibition decreases antibody-mediated rejection in sensitized renal transplant recipients. Am J Transplant. 2011;11(11):2405-2413.

107. Fan J, et al. Eculizumab salvage therapy for antibody-mediated rejection in a desensitizationresistant intestinal re-transplant patient. Am J Transplant. 2015;15(7):1995-2000.

108. Bentall A, et al. Antibody-mediated rejection despite inhibition of terminal complement. Transpl Int. 2014;27(12):1235-1243.

109. Cornell LD, Schinstock CA, Gandhi MJ, Kremers WK, Stegall MD. Positive crossmatch kidney transplant recipients treated with eculizumab: outcomes beyond 1 year. Am J Transplant. 2015;15(5):1293-1302.

110. Tillou X, et al. Recombinant human C1inhibitor prevents acute antibody-mediated rejection in alloimmunized baboons. Kidney Int . 2010;78(2):152-159.

111. Allhorn M, et al. The IgG-specific endoglycosidase EndoS inhibits both cellular and complement-mediated autoimmune hemolysis. Blood 2010;115(24):5080-5088

112. Lood C, et al. IgG glycan hydrolysis by endoglycosidase $\mathrm{S}$ diminishes the proinflammatory properties of immune complexes from patients with systemic lupus erythematosus: a possible new treatment? Arthritis Rheum. 2012;64(8):2698-2706.

113. Nandakumar KS, et al. Endoglycosidase treatment abrogates IgG arthritogenicity: importance of IgG glycosylation in arthritis. Eur J Immunol. 2007;37(10):2973-2982.

114. von Pawel-Rammingen U, Johansson BP, Björck L. IdeS, a novel streptococcal cysteine proteinase with unique specificity for immunoglobulin $G$. EMBO J. 2002;21(7):1607-1615.

115. Fishbein GA, Fishbein MC. Morphologic and immunohistochemical findings in antibodymediated rejection of the cardiac allograft. Hum Immunol. 2012;73(12):1213-1217.

116. Magil AB, Tinckam K. Monocytes and peritubular capillary C4d deposition in acute renal allograft rejection. Kidney Int. 2003;63(5):1888-1893.

117. Papadimitriou JC, et al. Glomerular inflammation in renal allografts biopsies after the first year: cell types and relationship with antibody-mediated rejection and graft outcome. Transplantation. 2010;90(12):1478-1485.

118. O'Leary JG, et al. Acute liver allograft antibody-mediated rejection: an inter-institutional study of significant histopathological features Liver Transpl. 2014;20(10):1244-1255.

119. Frank R, Dean SA, Molina MR, Kamoun M, Lal P. Correlations of lymphocyte subset infiltrates with donor-specific antibodies and acute antibody-mediated rejection in endomyocardial biopsies. Cardiovasc Pathol. 2015;24(3):168-172.

120. Huibers MM, et al. Donor-specific antibodies are produced locally in ectopic lymphoid structures in cardiac allografts. Am J Transplant. 2017;17(1):246-254.

121. Miyamoto E, et al. Association of local intrapulmonary production of antibodies specific to donor major histocompatibility complex class I with the progression of chronic rejection of lung allografts [published online ahead of print February 15, 2017]. Transplantation. https://doi. org/10.1097/TP.0000000000001665.

122. Fildes JE, et al. Natural killer cells in peripheral blood and lung tissue are associated with chronic rejection after lung transplantation. J Heart Lung Transplant. 2008;27(2):203-207.

123. Hidalgo LG, et al. NK cell transcripts and NK cells in kidney biopsies from patients with donor-specific antibodies: evidence for NK cell involvement in antibody-mediated rejection. Am J Transplant. 2010;10(8):1812-1822.

124. Loupy A, et al. Gene expression profiling for the identification and classification of antibody-mediated heart rejection. Circulation. 2017;135(10):917-935.

125. Petersson E, et al. Allogeneic heart transplantation activates alloreactive NK cells. Cell Immunol. 1997;175(1):25-32.

126.Venner JM, Hidalgo LG, Famulski KS, Chang J, Halloran PF. The molecular landscape of antibody-mediated kidney transplant rejection: evidence for NK involvement through CD16a Fc receptors. Am J Transplant. 2015;15(5):1336-1348.

127. Hirohashi T, et al. A novel pathway of chronic allograft rejection mediated by NK cells and alloantibody. Am J Transplant. 2012;12(2):313-321.

128. Kohei N, et al. Natural killer cells play a critical role in mediating inflammation and graft failure during antibody-mediated rejection of kidney allografts. Kidney Int. 2016;89(6):1293-1306.

129. Uehara S, et al. NK cells can trigger allograft vasculopathy: the role of hybrid resistance in solid organ allografts. J Immunol. 2005;175(5):3424-3430.

130. Zhang ZX, et al. Natural killer cells play a critica role in cardiac allograft vasculopathy in an interleukin-6-dependent manner. Transplantation. 2014;98(10):1029-1039.

131. Valenzuela NM, et al. Blockade of p-selectin is sufficient to reduce MHC I antibody-elicited monocyte recruitment in vitro and in vivo. $\mathrm{AmJ}$ Transplant. 2013;13(2):299-311.

132. Yamakuchi M, et al. Antibody to human leukocyte antigen triggers endothelial exocytosis. Proc Natl Acad Sci U S A. 2007;104(4):1301-1306.

133. Morrell CN, et al. In vivo platelet-endothelial cell interactions in response to major histocompatibility complex alloantibody. Circ Res. 2008;102(7):777-785.

134.Florey OJ, Johns M, Esho OO, Mason JC, Haskard DO. Antiendothelial cell antibodies mediate enhanced leukocyte adhesion to cytokineactivated endothelial cells through a novel mech- 
anism requiring cooperation between Fc $\gamma$ RIIa and CXCR1/2. Blood. 2007;109(9):3881-3889.

135. Valenzuela NM, Mulder A, Reed EF. HLA class I antibodies trigger increased adherence of monocytes to endothelial cells by eliciting an increase in endothelial P-selectin and, depending on subclass, by engaging Fc $\gamma$ Rs. J Immunol. 2013;190(12):6635-6650.

136. Valenzuela NM, Trinh KR, Mulder A, Morrison SL, Reed EF. Monocyte recruitment by HLA IgG-activated endothelium: the relationship between IgG subclass and Fc $\gamma$ RIIa polymorphisms. Am J Transplant. 2015;15(6):1502-1518.

137. Wu C, et al. Graft-infiltrating macrophages adopt an M2 phenotype and are inhibited by purinergic receptor $\mathrm{P} 2 \mathrm{X} 7$ antagonist in chronic rejection. Am J Transplant. 2016;16(9):2563-2573.

138. Parkes MD, Halloran PF, Hidalgo LG. Evidence for CD16a-mediated NK cell stimulation in antibody-mediated kidney transplant rejection. Transplantation. 2017;101(4):e102-e111.

139. Toyoda M, et al. IFN $\gamma$ production by NK cells from HLA-sensitized patients after in vitro exposure to allo-antigens. Transpl Immunol. 2012;26(2-3):107-112.

140.Shin BH, et al. Regulation of anti-HLA antibody-dependent natural killer cell activation by immunosuppressive agents. Transplantation. 2014;97(3):294-300.

141. Jin YP, et al. Anti-HLA class I antibody-mediated activation of the PI3K/Akt signaling pathway and induction of $\mathrm{Bcl}-2$ and $\mathrm{Bcl}-\mathrm{xL}$ expression in endothelial cells. Hum Immunol. 2004;65(4):291-302.

142.Jin YP, Korin Y, Zhang X, Jindra PT, Rozengurt E, Reed EF. RNA interference elucidates the role of focal adhesion kinase in HLA class I-mediated focal adhesion complex formation and proliferation in human endothelial cells. JImmunol. 2007;178(12):7911-7922.

143. Jin YP, Valenzuela NM, Ziegler ME, Rozengurt E, Reed EF. Everolimus inhibits anti-HLA I antibody-mediated endothelial cell signaling, migration and proliferation more potently than sirolimus. Am J Transplant. 2014;14(4):806-819.

144.Jindra PT, Jin YP, Rozengurt E, Reed EF. HLA class I antibody-mediated endothelial cell proliferation via the mTOR pathway. JImmunol. 2008;180(4):2357-2366.

145. Li F, Zhang X, Jin YP, Mulder A, Reed EF. Antibody ligation of human leukocyte antigen class I molecules stimulates migration and proliferation of smooth muscle cells in a focal adhesion kinase-dependent manner. Hum Immunol. 2011;72(12):1150-1159.

146.Ziegler ME, Jin YP, Young SH, Rozengurt E, Reed EF. HLA class I-mediated stress fiber formation requires ERK1/2 activation in the absence of an increase in intracellular $\mathrm{Ca}^{2+}$ in human aortic endothelial cells. Am J Physiol Cell Physiol. 2012;303(8):C872-C882.

147. Jindra PT, et al. Anti-MHC class I antibody activation of proliferation and survival signaling in murine cardiac allografts. JImmunol. 2008;180(4):2214-2224.

148.Lepin EJ, et al. Phosphorylated S6 ribosomal protein: a novel biomarker of antibody-mediated rejection in heart allografts. Am J Transplant. 2006;6(7):1560-1571.
149. Sellarés J, et al. Molecular diagnosis of antibody-mediated rejection in human kidney transplants. Am J Transplant. 2013;13(4):971-983.

150.Sis B, Jhangri GS, Bunnag S, Allanach K, Kaplan $\mathrm{B}$, Halloran PF. Endothelial gene expression in kidney transplants with alloantibody indicates antibody-mediated damage despite lack of $\mathrm{C} 4 \mathrm{~d}$ staining. Am J Transplant. 2009;9(10):2312-2323.

151. Afzali B, et al. Molecular assessment of microcirculation injury in formalin-fixed human cardiac allograft biopsies with antibody-mediated rejection. Am J Transplant. 2017;17(2):496-505.

152. Loupy A, et al. The Banff 2015 Kidney Meeting Report: Current Challenges in Rejection Classification and Prospects for Adopting Molecular Pathology. Am J Transplant. 2017;17(1):28-41.

153. Le Bas-Bernardet S, Coupel S, Chauveau A, Soulillou JP, Charreau B. Vascular endothelial cells evade apoptosis triggered by human leukocyte antigen-DR ligation mediated by allospecific antibodies. Transplantation. 2004;78(12):1729-1739.

154. Lion J, et al. HLA class II antibody activation of endothelial cells promotes Th17 and disrupts regulatory T lymphocyte expansion. Am J Transplant. 2016;16(5):1408-1420.

155. Kfoury AG, et al. Cardiovascular mortality among heart transplant recipients with asymptomatic antibody-mediated or stable mixed cellular and antibody-mediated rejection. J Heart Lung Transplant. 2009;28(8):781-784.

156. Rush DN, Henry SF, Jeffery JR, Schroeder TJ, Gough J. Histological findings in early routine biopsies of stable renal allograft recipients. Transplantation. 1994;57(2):208-211.

157. Moreso F, et al. Subclinical rejection associated with chronic allograft nephropathy in protocol biopsies as a risk factor for late graft loss. $\mathrm{Am} \mathrm{J}$ Transplant. 2006;6(4):747-752.

158.Wu GW, et al. Asymptomatic antibody-mediated rejection after heart transplantation predicts poor outcomes. J Heart Lung Transplant. 2009;28(5):417-422.

159. Bartlett AS, Ramadas R, Furness S, Gane E, McCall JL. The natural history of acute histologic rejection without biochemical graft dysfunction in orthotopic liver transplantation: a systematic review. Liver Transpl. 2002;8(12):1147-1153.

160. Michaels PJ, et al. Humoral rejection in cardiac transplantation: risk factors, hemodynamic consequences and relationship to transplant coronary artery disease. J Heart Lung Transplant. 2003;22(1):58-69.

161. Colvin MM, et al. Antibody-mediated rejection in cardiac transplantation: emerging knowledge in diagnosis and management: a scientific statement from the American Heart Association. Circulation. 2015;131(18):1608-1639.

162.Papadimitriou JC, et al. Histological grading of chronic pancreas allograft rejection/graft sclerosis. Am J Transplant. 2003;3(5):599-605.

163. Lund LH, et al. The registry of the International Society for Heart and Lung Transplantation: thirty-first official adult heart transplant report -2014; focus theme: retransplantation. J Heart Lung Transplant. 2014;33(10):996-1008.

164. Gaston RS, et al. Evidence for antibodymediated injury as a major determinant of late kidney allograft failure. Transplantation.
2010;90(1):68-74.

165. Kueckelhaus M, et al. Vascularized composite allotransplantation: current standards and novel approaches to prevent acute rejection and chronic allograft deterioration. Transpl Int. 2016;29(6):655-662.

166. Kaufman CL, et al. Graft vasculopathy in clinical hand transplantation. Am J Transplant. 2012;12(4):1004-1016.

167. Hachem RR, et al. Anti-human leukocyte antigen antibodies and preemptive antibody-directed therapy after lung transplantation. J Heart Lung Transplant. 2010;29(9):973-980.

168. Snyder LD, et al. Implications for human leukocyte antigen antibodies after lung transplantation: a 10-year experience in 441 patients. Chest. 2013;144(1):226-233.

169. Torrealba JR, et al. C4d-positive interacinar capillaries correlates with donor-specific antibodymediated rejection in pancreas allografts. Transplantation. 2008;86(12):1849-1856.

170.Del Bello A, et al. Prevalence, incidence and risk factors for donor-specific anti-HLA antibodies in maintenance liver transplant patients. $A m J$ Transplant. 2014;14(4):867-875.

171. Finlen Copeland CA, Snyder LD, Zaas DW, Turbyfill WJ, Davis WA, Palmer SM. Survival after bronchiolitis obliterans syndrome among bilateral lung transplant recipients. Am J Respir Crit Care Med. 2010;182(6):784-789.

172. DerHovanessian A, et al. Validation and refinement of chronic lung allograft dysfunction phenotypes in bilateral and single lung recipients. Ann Am Thorac Soc. 2016;13(5):627-635.

173. Williams WW, Taheri D, Tolkoff-Rubin N, Colvin RB. Clinical role of the renal transplant biopsy. Nat Rev Nephrol. 2012;8(2):110-121.

174. Galvani S, et al. A key role for matrix metalloproteinases and neutral sphingomyelinase- 2 in transplant vasculopathy triggered by anti-HLA antibody. Circulation. 2011;124(24):2725-2734.

175. Trayssac M, et al. Role of sphingosine-1-phosphate in transplant vasculopathy evoked by anti-HLA antibody. Am J Transplant. 2015;15(8):2050-2061.

176. Narayanan K, Jaramillo A, Phelan DL, Mohanakumar T. Pre-exposure to sub-saturating concentrations of HLA class I antibodies confers resistance to endothelial cells against antibody complement-mediated lysis by regulating Bad through the phosphatidylinositol 3-kinase/Akt pathway. Eur JImmunol. 2004;34(8):2303-2312.

177. Dong C, Wilson JE, Winters GL, McManus BM. Human transplant coronary artery disease: pathological evidence for Fas-mediated apoptotic cytotoxicity in allograft arteriopathy. $L a b$ Invest. 1996;74(5):921-931.

178. Tower CM, et al. Plasma C4d $\mathrm{d}^{+}$endothelial microvesicles increase in acute antibody-mediated rejection [published online ahead of print November 15, 2016]. Transplantation. https://doi. org/10.1097/TP.0000000000001572.

179. Singh N, et al. Circulating apoptotic endothelial cells and apoptotic endothelial microparticles independently predict the presence of cardiac allograft vasculopathy. J Am Coll Cardiol. 2012;60(4):324-331.

180. Gunasekaran M, et al. Donor-derived exosomes 
with lung self-antigens in human lung allograft rejection. Am J Transplant. 2017;17(2):474-484.

181. Reyes-Vargas E, Pavlov IY, Martins TB, Schwartz JJ, Hill HR, Delgado JC. Binding of anti-HLA class I antibody to endothelial cells produce an inflammatory cytokine secretory pattern. J Clin Lab Anal. 2009;23(3):157-160.

182. Bieri M, Oroszlan M, Farkas A, Ligeti N, Bieri J, Mohacsi P. Anti-HLA I antibodies induce VEGF production by endothelial cells, which increases proliferation and paracellular permeability. Int $J$ Biochem Cell Biol. 2009;41(12):2422-2430.

183. Lin CM, Plenter RJ, Coulombe M, Gill RG. Interferon gamma and contact-dependent cytotoxicity are each rate limiting for natural killer cellmediated antibody-dependent chronic rejection. Am J Transplant. 2016;16(11):3121-3130.

184.Kobashigawa JA, et al. Ten-year follow-up of a randomized trial of pravastatin in heart transplant patients. J Heart Lung Transplant. 2005;24(11):1736-1740.

185. Stojanovic I, et al. Survival, graft atherosclerosis, and rejection incidence in heart transplant recipients treated with statins: 5-year follow-up. J Heart Lung Transplant. 2005;24(9):1235-1238.
186.Gregory CR, et al. Treatment with rapamycin and mycophenolic acid reduces arterial intimal thickening produced by mechanical injury and allows endothelial replacement. Transplantation. 1995;59(5):655-661.

187. Keogh A, et al. Sirolimus in de novo heart transplant recipients reduces acute rejection and prevents coronary artery disease at 2 years: a randomized clinical trial. Circulation. 2004;110(17):2694-2700.

188. Matsuo Y, et al. Attenuation of cardiac allograft vasculopathy by sirolimus: relationship to time interval after heart transplantation. J Heart Lung Transplant. 2013;32(8):784-791.

189. Morice MC, et al. A randomized comparison of a sirolimus-eluting stent with a standard stent for coronary revascularization. N EnglJ Med. 2002;346(23):1773-1780.

190.Abe T, et al. Anti-huCD20 antibody therapy for antibody-mediated rejection of renal allografts in a mouse model. Am J Transplant. 2015;15(5):1192-1204.

191. Wiebe C, Nickerson P. Strategic use of epitope matching to improve outcomes. Transplantation. 2016;100(10):2048-2052.
192. Niederhaus SV, et al. Acute cellular and antibodymediated rejection of the pancreas allograft: incidence, risk factors and outcomes. Am J Transplant. 2013;13(11):2945-2955.

193. Gerlach UA, et al. Clinical relevance of the de novo production of anti-HLA antibodies following intestinal and multivisceral transplantation. Transpl Int. 2014;27(3):280-289.

194.Abu-Elmagd KM, et al. Preformed and de novo donor specific antibodies in visceral transplantation: long-term outcome with special reference to the liver. Am J Transplant. 2012;12(11):3047-3060.

195. de Serre NP, et al. Evaluation of c4d deposition and circulating antibody in small bowel transplantation. Am J Transplant. 2008;8(6):1290-1296.

196. Ruiz P, et al. Mucosal vascular alterations in the early posttransplant period of small bowel allograft recipients may reflect humoralbased allograft rejection. Transplant Proc. 2002;34(3):869-871.

197. Swanson BJ, Talmon GA, Wisecarver JW, Grant WJ, Radio SJ. Histologic analysis of chronic rejection in small bowel transplantation: mucosal and vascular alterations. Transplantation. 2013;95(2):378-382. 